\title{
Counteraction between two kinds of conditioned inhibition training
}

\author{
Gonzalo P. Urcelay and RalPh R. Miller \\ State University of New York, Binghamton, New York
}

\begin{abstract}
In a Pavlovian fear-conditioning preparation, we investigated the effects of combining Pavlovian and explicitly unpaired inhibition treatments. A summation test for inhibition suggested a strong tendency toward unpaired inhibition when that treatment was administered alone and found robust Pavlovian inhibition when that treatment was administered alone, but detected little behavior indicative of inhibition in subjects that experienced both treatments during training. The retardation test showed reliable unpaired and Pavlovian inhibition when these treatments were administered alone but no indication of inhibition in subjects that experienced both treatments. These counterintuitive results suggest that in some circumstances the effects of two inhibitory treatments are not additive but rather counteractive. The present results provide some information about the nature of conditioned inhibition and, more generally, cue interaction.
\end{abstract}

In a Pavlovian conditioning situation, cues are paired with biologically significant outcomes and later assessed for the capability to induce a change in behavior as a result of the pairings. One family of phenomena that has radically altered views of Pavlovian conditioning is cue interaction. By cue interaction, we mean that a cue's behavioral control can be affected by that of a second cue, provided the two cues are trained together. For example, with Pavlovian conditioned inhibition treatment, subjects learn that one cue (A) is consistently followed by the outcome $(+)$, but that the same cue presented in compound with a second cue $(\mathrm{X})$ is not $(\mathrm{A}+1$ $\mathrm{AX}-$ ). As a consequence of this training, $\mathrm{X}$ becomes a conditioned inhibitor capable of passing both summation and retardation tests for inhibition (Rescorla, 1969).

Recent studies in the excitatory domain have reported that combining two treatments that establish different companions for a target cue can result in a net effect that is not additive, as one might expect, but counteractive. For example, training with massed target-outcome presentations leads to weak behavioral control, presumably because the training context competes with the target for behavioral control (trial-massing effect). Similarly, if one trains a target in the presence of a more salient cue, behavioral control by the target is impaired (overshadowing), presumably because the more salient cue competes for behavioral control with the target. However, Stout, Chang, and Miller (2003) have reported that combining trial massing with overshadowing treatment does not result in decreased behavioral control, but in heightened behavioral control by the target when compared with either overshadowing alone or massed trials with the target cue alone.

Although this counterintuitive outcome is problematic for theories focused on acquisition processes (e.g., Res- corla \& Wagner, 1972; Wagner, 1981), it is consistent with a model focused on retrieval processes. The extended comparator hypothesis (ECH; Denniston, Savastano, \& Miller, 2001; Stout \& Miller, 2007) posits that cue interaction effects occur because of competition during testing. Furthermore, it predicts that in select situations in which the target cue has more than one competitor, the effects of these competitors will tend to cancel each other (as long as the two competitors have a direct association with each other). Applied to the example above, ECH posits that massing trials establishes the training context as a comparator and that overshadowing treatment establishes the overshadowing cue as a comparator. As these cues are trained together, they cancel each other rather than summate in their competition with the target. The net result is little decrement in conditioned responding to the target. Other studies have observed similar counteractions between overshadowing and treatments that increase contextual associative strength, such as the outcome-alone exposure effect (Urushihara \& Miller, 2006) and the degraded contingency effect (Urcelay \& Miller, 2006b).

The studies reviewed above suggest that the presence of two competing (interacting) cues during excitatory training does not always result in a larger decrement in responding than does the presence of either cue alone. These examples all demonstrate counteraction in the excitatory domain. In conditioned inhibition, the presence of an excitatory cue during nonreinforced trials with the target is the main force driving inhibition, in that posttraining extinction of the excitatory cue often decreases conditioned inhibition (Lysle \& Fowler, 1985). What would happen if conditioned inhibition were trained with two excitatory cues? In recent experiments, Urcelay and

R. R.Miller, rmiller@binghamton.edu 
Miller (2006a) observed little Pavlovian conditioned inhibition (A+/AX - interspersed) after training with massed trials. Presumably, in Pavlovian inhibition treatment, A is the training excitor and $\mathrm{X}$ becomes inhibitory after being paired with A on nonreinforced trials. However, Urcelay and Miller trained with massed trials, which should also have established the context as an excitor (i.e., associated to the outcome), an associate of A, and an associate of X. Since $\mathrm{X}$ in this situation had two excitors (A and the context) that were themselves associated, ECH anticipates that their effects should have canceled each other and, consequently, little inhibition to X should have been observed, which is what occurred. Moreover, consistent with this expectation, they observed that Pavlovian inhibition returned when the training context was extinguished after inhibitory training.

The experiment reported here was inspired by the results of Urcelay and Miller (2006a) and by those other studies mentioned above that showed counteraction between treatments in the excitatory domain. In explicitly unpaired inhibition treatment, subjects experience interspersed trials of the outcome alone and of the target inhibitor unpaired with the outcome $(+/ \mathrm{X}-)$. Thus, the context becomes excitatory, and the target inhibitor is presented alone in the excitatory context. The context takes the role of the excitor analogous to the training excitor $\mathrm{A}$ in Pavlovian inhibition training $(\mathrm{A}+/ \mathrm{AX}-)$. According to the Rescorla-Wagner model, explicitly unpaired training interspersed with Pavlovian conditioned inhibition training should speed acquisition of inhibition because the expectancy of the US on each AX nonreinforced trial should be larger than that on a group that does not experience additional explicitly unpaired inhibition training. According to ECH, establishing two excitors for the target inhibitor (A, because of Pavlovian inhibition training, and the training context, because of explicitly unpaired training) should diminish conditioned inhibition because the target would have two excitors that cancel each other as a result of their being trained together. The present study tested these divergent predictions. Two groups of rats experienced Pavlovian inhibition training, two groups experienced explicitly unpaired inhibition training, and two groups experienced both Pavlovian and unpaired inhibition training (see Table 1). Subsequently, summation and retardation tests for conditioned inhibition were administered. One group from each of the three training conditions was tested for summation, and the remaining group served as a control. After summation testing, the target group for summation served as a control for retardation, whereas the control group for summation - which was not exposed to the inhibitor during the summation test - experienced retardation testing. This strategy has been used successfully in the past (e.g., Urcelay \& Miller, 2006a).

\section{METHOD}

\section{Subjects}

Subjects were 36 female (198-259 g) and 36 male (267-372 g) Sprague-Dawley, experimentally naive adult rats bred in our colony. Subjects were individually housed and maintained on a 16-h light, 8-h dark cycle with experimental sessions occurring roughly midway through the light portion. Subjects had free access to food in the home cage. One week prior to initiation of the experiment, water availability was progressively reduced to $20 \mathrm{~min}$ per day, provided approximately $2 \mathrm{~h}$ after any scheduled treatment.

\section{Apparatus}

Six instances of each of two chambers (V and R) were used. Chamber V was the shape of a vertical, truncated V, $27 \mathrm{~cm}$ long, $29.5 \mathrm{~cm}$ high, $21.5 \mathrm{~cm}$ wide at the top, and $5.5 \mathrm{~cm}$ wide at the bottom. The ceiling was clear Plexiglas, the front and back walls were black Plexiglas, and the sidewalls were stainless steel. The floor consisted of two $27-\mathrm{cm}$ long plates, $2 \mathrm{~cm}$ wide, with a $1.5-\mathrm{cm}$ gap between the plates. A footshock could be delivered through the metal walls and floor of the chamber. Each chamber was illuminated by a 7-W (nominal at $120 \mathrm{VAC}$, but driven at $60 \mathrm{VAC}$ ) light bulb wall mounted $30 \mathrm{~cm}$ from the center of the experimental chamber.

Chamber $\mathrm{R}$ was rectangular, measuring $24.0 \times 9.0 \times 12.5 \mathrm{~cm}$ $(1 \times w \times h)$. The walls and ceiling of Chamber R were clear Plexiglas, and the floor was comprised of stainless steel rods measuring $0.5 \mathrm{~cm}$ in diameter, spaced $1.5 \mathrm{~cm}$ apart (center to center). The rods were connected by NE-2 bulbs, which allowed for the delivery of footshock. Each chamber was illuminated by a 2-W (nominal at 120 $\mathrm{VAC}$, but driven at $60 \mathrm{VAC}$ ) wall-mounted light. The light intensities inside the two chamber types were approximately equal, due to the difference in opaqueness of the walls of Chambers $\mathrm{V}$ and $\mathrm{R}$.

Each chamber was housed in a separate light- and soundattenuating isolation chest. All chambers could be equipped with a water-filled lick tube that extended $1 \mathrm{~cm}$ into a cylindrical niche, which was $4.5 \mathrm{~cm}$ in diameter, left-right centered on a narrow wall of the chamber, with its bottom $1.75 \mathrm{~cm}$ above the floor of the apparatus and $5.0 \mathrm{~cm}$ deep. A photobeam $1 \mathrm{~cm}$ in front of the lick tube was broken whenever the subject licked the tube. Three speakers on the inside walls of the isolation chests could deliver a 500- and 520-Hz complex tone $8 \mathrm{~dB}$ (C-scale) above background $(76 \mathrm{~dB}$, produced mainly by a ventilation fan), a click train $(6 \mathrm{~Hz}) 8 \mathrm{~dB}$ above background, or a white noise stimulus, $8 \mathrm{~dB}$ above background. A visual stimulus

Table 1

Experimental Design

\begin{tabular}{lllcccc}
\hline \multicolumn{1}{c}{ Group } & $\begin{array}{c}\text { Preexp } \\
\text { Ctx 1 }\end{array}$ & $\begin{array}{c}\text { Phase 1 } \\
\text { Inhibition Training Ctx 2 }\end{array}$ & $\begin{array}{c}\text { Phase 2 } \\
\text { Transfer } \\
\text { Training Ctx 1 }\end{array}$ & $\begin{array}{c}\text { Sum } \\
\text { Test } \\
\text { Ctx 1 }\end{array}$ & $\begin{array}{c}\text { Retard } \\
\text { Training } \\
\text { Ctx 2 }\end{array}$ & $\begin{array}{c}\text { Retard } \\
\text { Test } \\
\text { Ctx 1 }\end{array}$ \\
\hline Pav-Sum & $4 \mathrm{X}-/ 4 \mathrm{Y}-$ & $72 \mathrm{~A}+/ 120 \mathrm{AX}-$ & $4 \mathrm{~B}+$ & $\mathrm{BX}$ & $4 \mathrm{Y}+$ & $\mathrm{Y}$ \\
Pav-Ret & $4 \mathrm{X}-/ 4 \mathrm{Y}-$ & $72 \mathrm{~A}+/ 120 \mathrm{AX}-$ & $4 \mathrm{~B}+$ & $\mathrm{BY}$ & $4 \mathrm{X}+$ & $\mathrm{X}$ \\
Unp-Sum & $4 \mathrm{X}-/ 4 \mathrm{Y}-$ & $72+/ 120 \mathrm{X}-$ & $4 \mathrm{~B}+$ & $\mathrm{BX}$ & $4 \mathrm{Y}+$ & $\mathrm{Y}$ \\
Unp-Ret & $4 \mathrm{X}-/ 4 \mathrm{Y}-$ & $72+/ 120 \mathrm{X}-$ & $4 \mathrm{~B}+$ & $\mathrm{BY}$ & $4 \mathrm{X}+$ & $\mathrm{X}$ \\
P+U-Sum & $4 \mathrm{X}-/ 4 \mathrm{Y}-$ & $72 \mathrm{~A}+/ 120 \mathrm{AX}-/ 72+/ 120 \mathrm{X}-$ & $4 \mathrm{~B}+$ & $\mathrm{BX}$ & $4 \mathrm{Y}+$ & $\mathrm{Y}$ \\
P+U-Ret & $4 \mathrm{X}-/ 4 \mathrm{Y}-$ & $72 \mathrm{~A}+/ 120 \mathrm{AX}-/ 72+/ 120 \mathrm{X}-$ & $4 \mathrm{~B}+$ & $\mathrm{BY}$ & $4 \mathrm{X}+$ & $\mathrm{X}$ \\
\hline
\end{tabular}

Note $-\mathrm{X}$ and $\mathrm{Y}=$ white noise and tone, counterbalanced; $\mathrm{A}=$ flashing light; $\mathrm{B}=$ clicks; + = footshock; - denotes no reinforcement. / denotes that trials were interspersed. $\mathrm{Ctx}=$ context; Pav $=$ Pavlovian inhibition training; Unp = Unpaired inhibition training; $\mathrm{P}+\mathrm{U}=$ Pavlovian and unpaired inhibition training; Ret = retardation; Sum $=$ summation. Numbers next to the pairings indicate total number of each type of trial during training. 
consisting of a flashing light ( $0.25 \mathrm{sec}$ on, $0.25 \mathrm{sec}$ off $)$ could also be presented. The light was provided by either a $25-\mathrm{W}$ bulb (Chamber $\mathrm{R}$ ) or a $100-\mathrm{W}$ bulb (Chamber V), both nominal at 120 VAC but driven at $60 \mathrm{VAC}$. The bulbs were mounted on an inside wall of the environmental chest, $30 \mathrm{~cm}$ from the center of the experimental chamber. A constant-current, $1.0-\mathrm{mA}$ footshock, which served as the outcome, could be delivered through the floors of both types of chambers. The tone, white noise, light, and click CSs were all $10 \mathrm{sec}$ in duration, and the footshock outcome $(+)$ was $0.5 \mathrm{sec}$ in duration. On all reinforced trials, the outcome was initiated at cue termination. The flashing light served as CS $A$, the click train as CS $B$, and the white noise and complex tone as CSs $X$ and $Y$, counterbalanced within groups.

\section{Procedure}

Subjects were randomly assigned to one of six groups: PavlovianSummation (Pav-Sum), Pavlovian-Retardation (Pav-Ret), UnpairedSummation(Unp-Sum), Unpaired-Retardation(Unp-Ret), Pavlovian+ Unpaired-Summation $(\mathrm{P}+\mathrm{U}-\mathrm{Sum})$ and Pavlovian + UnpairedRetardation $(\mathrm{P}+\mathrm{U}-\mathrm{Ret})$, counterbalanced for $\operatorname{sex}(n \mathrm{~s}=12)$. Phase 1 and retardation-test training were conducted in one context, inhibition training, $(\mathrm{V}$ or $\mathrm{R})$; all other treatments were conducted in the remaining context, test, with the two types of contexts counterbalanced within groups. This was done to prevent differential fear of the training context from summating with fear of the CS.

Acclimation and preexposure. On Days 1 and 2, subjects were exposed to the test chamber during daily 60 -min sessions with lick tubes present. On both days, stimuli $X$ and $Y$ were each presented twice, interspersed 10,25,30, and 50 min into each session, in order to reduce unconditioned fear of these cues.

Phase 1: Inhibitory training. Prior to Phase 1, the lick tubes were removed from the inhibition training chambers. On Days 3-14, during daily 60 -min sessions, subjects in the Pav condition received $6 \mathrm{~A}+$ trials and $10 \mathrm{AX}-$ trials. Subjects in the Unp condition received 6 unsignaled outcome trials and $10 \mathrm{X}-$ trials. Subjects in the $\mathrm{P}+\mathrm{U}$ condition experienced $6 \mathrm{~A}+$ trials, $10 \mathrm{AX}-$ trials, $6 \mathrm{X}-$ trials, and 10 unsignaled presentations of the outcome. The mean intertrial interval for the 16 trials (Pav and Unp) was $3.5 \mathrm{~min}$ (range: 3-4), and for the 32 trials $(\mathrm{P}+\mathrm{U})$, was of $1.75 \mathrm{~min}$ (range: 1.25-2.25).

Transfer training. On Day 15, all subjects received in the test context four reinforced trials with a transfer excitor $(\mathrm{B}+)$, to be used in the summation test. Session duration was $60 \mathrm{~min}$, and trials occurred at 5, 30, 43, and 54 minutes.

Reacclimation. To restabilize baseline drinking, the lick tubes were reinserted on Days 16 and 17, and subjects were allowed to drink during daily 60 -min sessions in the test context.

Summation testing. On Day 18, with the lick tubes inserted in the test context, all subjects were tested for suppression to the transfer excitor B in the presence of the conditioned inhibitor X (PavSum, Unp-Sum, and P+U-Sum) or an irrelevant stimulus Y (PavRet, Unp-Ret, and $\mathrm{P}+\mathrm{U}-$ Ret). This was accomplished by presenting compound BX or BY immediately upon completion of 5 cumulative sec of licking. Thus, all subjects were drinking at the time of CS onset. The time to complete this initial 5 cumulative sec of licking (pre-CS score) and the time to complete 5 additional sec after onset of the test CS (CS score) were recorded. Test sessions were $16 \mathrm{~min}$ in duration, with a ceiling of $15 \mathrm{~min}$ being imposed on CS score. All subjects received exactly $15 \mathrm{~min}$ of exposure to BX or BY.

Retardation training. On Day 19, in the inhibition training context with the lick tubes absent, subjects in the Ret condition experienced four reinforced trials with the target stimulus $(\mathrm{X}+)$, and subjects in the Sum condition experienced four reinforced trials with a control CS $(\mathrm{Y}+)$ in order to assess the capacity of the putative inhibitor to become a conditioned excitor. Importantly, the groups that were tested with target stimulus $\mathrm{X}$ on the summation test (Pav-Sum, Unp-Sum, and P+U-Sum) served as controls for the retardation test, whereas those groups that served as controls in the summation test (Pav-Ret, Unp-Ret, and P+U-Ret) were, in this phase, trained and tested with the target stimulus X. Session duration was $30 \mathrm{~min}$, and reinforced trials occurred at 4, 9, 17, and $22 \mathrm{~min}$.
Reacclimation. On Days 20 and 21, the lick tubes were reinserted, and subjects were allowed to drink during daily 60 -min sessions in the test context.

Retardation testing. On Day 22, with the lick tubes inserted in the test context, subjects were tested for suppression to the target CS X (Pav-Ret, Unp-Ret, and P+U-Ret) or to the control CS Y (Pav-Sum, Unp-Sum, and $\mathrm{P}+\mathrm{U}-\mathrm{Sum}$ ) by presenting $\mathrm{X}$ or Y, respectively, immediately upon completion of 5 cumulative sec of licking. Times to complete this initial 5 cumulative sec of licking (pre-CS score) and to complete 5 additional sec after the onset of the test CS (CS score) were recorded. Test sessions were 16 min long, with a 15-min ceiling imposed on CS score.

Scores were transformed to $\log$ (base 10) scores to approximate a normal distribution within groups, thereby justifying the use of parametric statistics.

\section{RESULTS AND DISCUSSION}

Figure 1 shows the summation test results. Robust Pavlovian inhibition is evidenced by less responding to the compound BX than to the compound BY. Unpaired inhibition seems apparent in the figure, but not as robust as Pavlovian inhibition. Critically, no tendency toward conditioned inhibition is apparent in groups that experienced both inhibitory treatments. These impressions were confirmed by the following analyses.

A $3 \times 2$ ANOVA with type of inhibition training (Pav vs. Unp vs. $\mathrm{P}+\mathrm{U}$ ) and test stimulus (BX vs. BY, in which the summation groups were tested on BX and the control groups on BY) performed on the transformed pre-CS scores revealed no main effects nor interaction (all $p \mathrm{~s}>$ .34 ), indicating that groups did not differ appreciably in their fear of the test context. A similar ANOVA performed on suppression scores during presentation of the compound stimuli revealed a main effect of inhibition training $\left[F(2,66)=6.77, p<.01, M S_{\mathrm{e}}=0.09\right]$, a main effect of test stimulus $\left[F(1,66)=6.78, p<.05, M S_{\mathrm{e}}=0.09\right]$, and a marginally significant interaction $[F(2,66)=2.82, p=$ $\left..066, M S_{\mathrm{e}}=0.09\right]$. Planned comparisons using the overall error term from the ANOVA demonstrated less suppression to $\mathrm{BX}$ than to $\mathrm{BY}$ in the groups that experienced

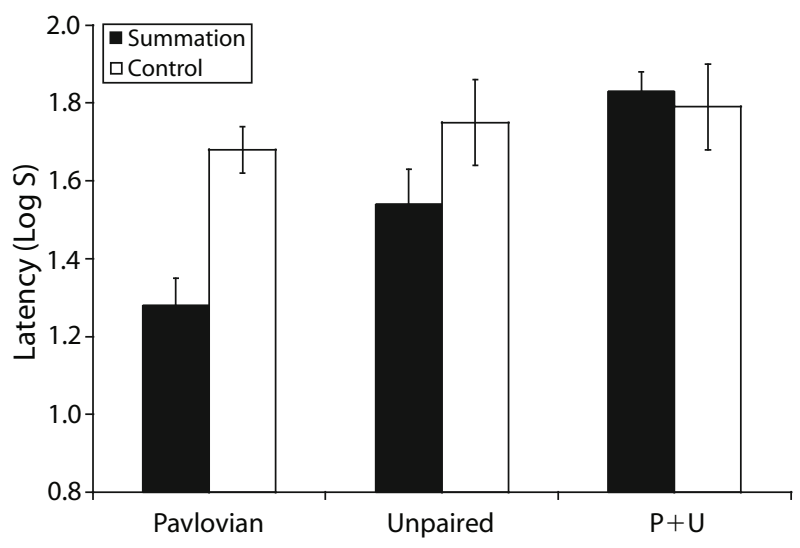

Figure 1. Mean times to complete 5 cumulative sec of drinking upon presentation of the target CSs on the summation test. Summation subjects were tested on BX. Control subjects were tested on BY. Error bars denote standard error of the mean. See Table 1 for treatments. 
Pavlovian inhibition training $[F(1,66)=9.56, p<.01]$. A similar comparison between the two groups that experienced unpaired inhibition revealed a marginal difference between the two groups $[F(1,66)=2.80, p=.09]$. Suppression in the two groups that experienced both treatments did not differ $[F(1,66)=0.06, p=.79]$.

The retardation test results are shown in Figure 2. Subjects in the groups trained with Pavlovian inhibition showed less suppression to the target stimulus $\mathrm{X}$ than to $\mathrm{Y}$. A similar pattern was observed in subjects trained with unpaired inhibition, but not in subjects that were trained with both procedures. These impressions were confirmed by the following analyses.

Analysis of the pre-CS scores from the retardation test were conducted with a $3 \times 2$ ANOVA with type of inhibition training (Pav vs. Unp vs. $\mathrm{P}+\mathrm{U}$ ) and test stimulus (X vs. Y) as factors. This analysis did not reveal any main effects or interaction (all $p \mathrm{~s}>.5$ ). A similar analysis conducted on the suppression latencies in the presence of $\mathrm{X}$ or $\mathrm{Y}$ indicated a main effect of inhibition training $\left[F(2,66)=16.21, p<.001, M S_{\mathrm{e}}=0.07\right]$, a main effect of test stimulus $\left[F(1,66)=27.31, p<.001, M S_{\mathrm{e}}=0.07\right]$, and an interaction $\left[F(2,66)=6.20, p<.01, M S_{\mathrm{e}}=0.07\right]$. Planned comparisons using the overall error term from the ANOVA revealed retarded acquisition in the Pavlovian group in relation to its control $[F(1,66)=16.58, p<$ $.001]$. A similar pattern was evidenced in the two groups trained with the unpaired procedure $[F(1,66)=23.11$, $p<.001]$, but not in the two groups trained with both treatments $[F(1,66)=0.03, p=.86]$.

The present experiment was conducted to assess the effect of training a single cue with two inhibitory procedures. In the summation test, we observed robust Pavlovian inhibition $(\mathrm{A}+/ \mathrm{AX}-)$, a strong tendency toward unpaired inhibition $\left(+/ \mathrm{X}^{-}\right)$, and no behavior indicative of inhibition in subjects trained with both treatments together $(\mathrm{A}+/ \mathrm{AX}-/+/ \mathrm{X}-)$. The retardation test showed retarded emergence of excitation after Pavlovian inhibition and un-

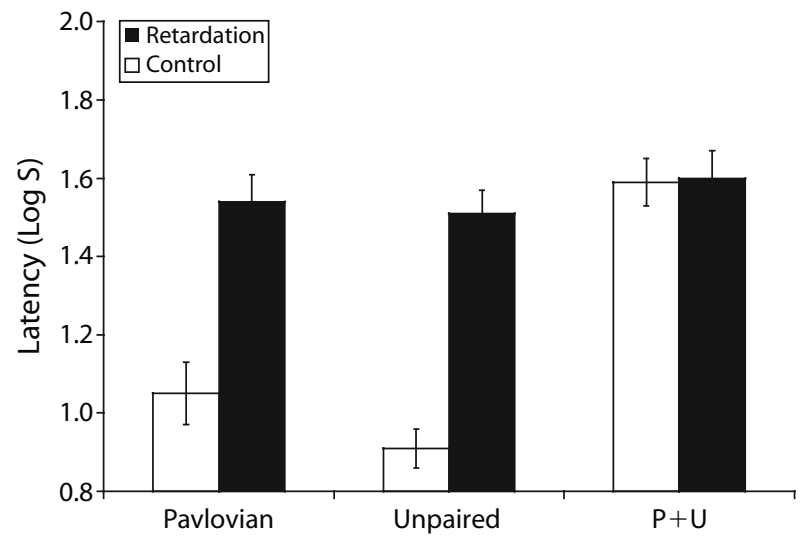

Figure 2. Mean times to complete 5 cumulative sec of drinking upon presentation of the target CS on the retardation test. Retardation subjects were tested on $X$. Control subjects were tested on Y. Error bars denote standard error of the mean. See Table 1 for treatments. paired inhibition treatments, but no retardation when the two treatments were administered together.

As inferred from both summation and retardation tests for inhibition, Pavlovian inhibition was robust. Unpaired inhibition was weaker than Pavlovian inhibition, as evidenced by the marginally significant difference in the summation test. This outcome was expected under the present training conditions because we used the same session length for training both procedures, and previous research suggests that, for strong unpaired inhibition to be observed, training has to be conducted with massed trials (Hearst \& Franklin, 1977). Unpaired inhibition relies on the training context being highly excitatory for inhibition to be observed, because the training context is the only stimulus that is consistently reinforced during training. The opposite is true for Pavlovian inhibition; Urcelay and Miller (2006a) did not observe Pavlovian inhibition with massed training trials. In the present experiment, we used intermediate trial spacing for both procedures, which was probably too spaced for us to observe robust unpaired inhibition. However, this does not undermine the fact that neither test revealed inhibition in the groups that experienced both inhibition treatments. In these groups, the unpaired inhibition treatment made trials more massed than in the Pavlovian condition alone, and consequently the context should have had more excitatory value than with Pavlovian or unpaired treatment alone. Thus, as we explain below, any - even nonsignificantadditional unpaired training makes the predictions of models that emphasize acquisition (Rescorla \& Wagner, 1972; Wagner, 1981) and those of ECH diverge.

The results observed in the groups trained with both inhibitory treatments are inconsistent with models that emphasize interactions among simultaneously trained cues as resulting from processes that take place during acquisition. For example, the Rescorla-Wagner (1972) model explains inhibition as the result of an expectation of the outcome evoked by the presence of an excitatory stimulus that is not fulfilled on a nonreinforced trial. This model predicts that $\mathrm{X}$ should have acquired inhibition in the Pavlovian condition. Although, with US-alone trials, the context should have attenuated learning to the excitor A (blocking by the context), on nonreinforced trials $(\mathrm{AX}-$ and $\mathrm{X}-$ ), it should have enhanced the discrepancy of the expected outcome, and, consequently, inhibition should have developed faster. Thus, the added unpaired training should have accelerated the development of inhibition instead of canceling any inhibition developed as a result of the Pavlovian procedure. Wagner's (1981) SOP offers a similar prediction. According to this model, inhibitory associations develop when the intended inhibitor is physically present, its representation in state $\mathrm{A} 1$, and the outcome representation is activated into state A2. As applied to this experiment, the excitor A and the training context conjointly should have activated a fuller representation of outcome elements into A2 on each AXnonreinforced trial. As much or more inhibition should, therefore, have been observed than with either inhibition treatment alone, which is contrary to the absence of inhibition observed in the groups experiencing both treat- 
ments. In other words, according to these models, if the inhibitor is presented together with the training excitor in a highly excitatory context, inhibition should be achieved faster, because the expectation of the outcome on a nonreinforced trial should be greater in the presence of two excitatory cues.

ECH (Denniston et al., 2001; Stout \& Miller, 2007) explains inhibition as being the interaction between associations of null or positive value, but not of negative value. According to this model, the presentation of the target cue at test in Pavlovian inhibition indirectly activates a representation of the outcome mediated by excitor A. This decreases responding to the inhibitor, as well as to any cue present with it, thereby inducing behavior indicative of inhibition. A similar explanation is put forth by $\mathrm{ECH}$ to predict unpaired inhibition, the difference being that the training context plays the role of the excitor. A completely different prediction is made by the ECH when both treatments are administered together. Now the target inhibitor should have two excitors, or comparator stimuli-A and the training context. Moreover, the effects of the two comparators should tend to cancel each other; thus, little behavior indicative of inhibition is expected. This explanation is consistent with the present results. Note that this mechanism only applies when the two treatments that are combined establish different excitors. For example, combining explicitly unpaired inhibition $(+/ \mathrm{X})$ with differential inhibition $(\mathrm{A}+/ \mathrm{X}-)$ should enhance inhibition rather than decrease it because both treatments rely on the training context for the observation of inhibition.

In a broader sense, these results suggest that the interaction between cues trained together may not be as simple a process as we have previously thought. Specifically, they suggest that the effects of multiple competing cues are not always additive. Thus, the assumption that inhibition arises based on a monolithic expectation of the US that is not fulfilled might not be correct, because in the present experiment, a larger outcome expectation did not result in more behavior indicative of inhibition. Similarly, experiments have demonstrated counteraction effects between response-degrading treatments in excitatory conditioning. Stout et al. (2003) observed counteraction between overshadowing treatment and trial massing. Urushihara and Miller (2006) saw similar counteraction between overshadowing treatment and outcome-alone exposure, and Urcelay and Miller (2006b) observed counteraction with overshadowing and degraded contingency treatment. Here we report counteraction between two inhibitory treat- ments, which generalizes these counteraction effects from the excitatory domain to the inhibitory domain.

\section{AUTHOR NOTE}

Support for this research was provided by National Institute of Mental Health Grant 33881. The authors thank David Guez, Bridget McConnell, Heather Sissons, Kouji Urushihara, Daniel Wheeler, and James Witnauer for their comments on an earlier version of this article, and Alyssa Orinstein for help in conducting the experiment. Inquiries should be addressed to Ralph Miller, Department of Psychology, SUNY-Binghamton, Binghamton, NY 13902-6000 (e-mail: rmiller@binghamton.edu).

\section{REFERENCES}

Denniston, J. C., Savastano, H. I., \& Miller, R. R. (2001). The extended comparator hypothesis: Learning by contiguity, responding by relative strength. In R. R. Mowrer \& S. B. Klein (Eds.), Handbook of contemporary learning theories (pp. 65-117). Hillsdale, NJ: Erlbaum.

Hearst, E., \& Franklin, S. R. (1977). Positive and negative relations between a signal and food: Approach-withdrawal behavior to the signal. Journal of Experimental Psychology: Animal Behavior Processes, 3, 37-52.

Lysle, D. T., \& Fowler, H. (1985). Inhibition as a "slave” process: Deactivation of conditioned inhibition through extinction of conditioned excitation. Journal of Experimental Psychology: Animal Behavior Processes, 11, 71-94.

ResCorla, R. A. (1969). Pavlovian conditioned inhibition. Psychological Bulletin, 72, 77-94.

Rescorla, R. A., \& Wagner, A. R. (1972). A theory of Pavlovian conditioning: Variations in the effectiveness of reinforcement and nonreinforcement. In A. H. Black \& W. F. Prokasy (Eds.), Classical conditioning II: Current research and theory (pp. 64-99). New York: Appleton-Century-Crofts.

Stout, S. C., Chang, R., \& Miller, R. R. (2003). Trial spacing is a determinant of cue interaction. Journal of Experimental Psychology: Animal Behavior Processes, 29, 23-38.

Stout, S. C., \& Miller, R. R. (2007). Sometimes competing retrieval (SOCR): A formalization of the comparator hypothesis. Psychological Review, 114, 759-783.

Urcelay, G. P., \& Miller, R. R. (2006a). A comparator view of Pavlovian and differential inhibition. Journal of Experimental Psychology: Animal Behavior Processes, 32, 271-283.

Urcelay, G. P., \& Miller, R. R. (2006b). Counteraction between overshadowing and degraded contingency treatments: Support for the extended comparator hypothesis. Journal of Experimental Psychology: Animal Behavior Processes, 32, 21-32.

Urushihara, K., \& Miller, R. R. (2006). Overshadowing and the outcome-alone exposure effect counteract each other. Journal of Experimental Psychology: Animal Behavior Processes, 32, 253-270.

WAGNER, A. R. (1981). SOP: A model of automatic memory processing in animal behavior. In N. E. Spear \& R. R. Miller (Eds.), Information processing in animals: Memory mechanisms (pp. 5-47). Hillsdale, NJ: Erlbaum.

(Manuscript received January 31, 2007; revision accepted for publication June 12, 2007.) 